\section{Öğrenen Öğretmen, "Cahil Hoca” Olabilir mi?}

Kevser Yıldırım ${ }^{1}$

http://dx.doi.org/10.22596/

cresjournal.0102.70.74

\title{
Eleştirel
}

Inceleme

\section{Critical}

Review

$$
\begin{array}{r}
\text { bittïn münkiülerin kyjenda... } \\
\text { Turgut Uyar }
\end{array}
$$

Özet

Bu yazıda, Jacques Rancière’in Cahil Hoca kitabında ortaya koyduğu eğitim yaklaşımı, "öğrenci merkezli eğitim” ve "ögrenmeyi öğrenme” gibi günümüz pedagojik yaklaşımlarının başat kavramlarıyla benzerlikleri açısından değerlendirilmektedir. Bu değerlendirmenin, belirtilen kavramların farklı yönlerden incelenmesi ve eğitimde eşitlik konusunda disiplinler arası yeni doğrultuların oluşturulması açısından eğitim bilimleri alanına katkı sağlaması umulmaktadır.

Anahtar kelimeler: Cahil Hoca, eğitim felsefesi, eşitlik, evrensel eğitim, Jacques Rancière, Joseph Jacotot, ögrenen ögretmen

\section{Can The Teacher as a Learner be "The Ignorant Schoolmaster"?}

\section{Abstract}

In this article, the educational approach that Jacques Rancière put forward in the book of The Ignorant Schoolmaster is evaluated in terms of similarities with the dominant concepts of today's pedagogical approaches such as "student-centered education" and "learning to learn". It is hoped that this evaluation will contribute to the field of educational sciences in terms of analyzing the concepts mentioned from different angles and creating new interdisciplinary directions on equality in education.

Keywords: equality, The Ignorant Schoolmaster, Jacques Rancière, Joseph Jacotot, philosophy of education, teacher as a learner, universal education

1 Dr,Danışman, YenidoğuEğitimKurumları,editorkevser@hotmail.com.ORCID:0000-0003-2237-9739 Lisansını tarih, yüksek lisansını eğitim yönetimi ve denetimi, doktorasını eğitim teknolojisi alanında yapmıştır. Farklı kurumlarda öğretmenlik, editörlük, eğitim yöneticiliği gibi görevler yapmışolan Yıldırım, halihazırda Yenidoğu Eğitim Kurumlarında eğitim-araştırma danışmanlığı yapmakta ve eğitim teknolojisi, öğretmen eğitimi, araştırmacı öğretmenlik, çocuklarla araştırma, sosyal bilimlerde araştırma yöntemleri, eğitim araştırmaları felsefesi ve eğitim bilimleri felsefesi alanlarında bağımsız araştırmacı olarak çalışmaya devam etmektedir. Ayrıca, sosyal bilimler ve felsefeokumalarıyoluyla, eğitimteorisiveeğitimfelsefesiüzerindedüşünmeyedevametmektedir.

\section{Künye:}

Kitabın Adı

Cahil Hoca: Zihinsel Özgürleşme Üstüne Beş Ders.

Yazar(lar)

Jacques Rancière

Cevirmen

Şavaş Kılıç

ISBN

978-975-342-966-5

Sayfa Ebatı, Sayısı

$13 \times 19,5 \mathrm{~cm}, 144 \mathrm{~s}$.

Kapak/Kağıt/Renk

Karton Kapak, Kitap Kağıdı,

Tek Renk

Baskı Sayısı ve Yılı

1. Baskı, Ekim 2014, İstanbul

Dil

Türkçe

Yayınevi

Metis Yayınları

Başvuru/Submitted

28 Tem/July 2020

Kabul/Accepted

28 Ağu/Aug 2020

Yayın/Published

28 Eyl/Sep 2020

ISSN

2718-0808

Atıf/Cite: Yıldırım, K. (2020). Öğrenen öğretmen, "Cahil Hoca" olabilir mi? Alanyazin, 1(2), 70-74. 


\section{Öğrenen Öğretmen, “Cahil Hoca” Olabilir mi?}

Aslen Fransiz olan Joseph Jacotot 1818'de sürgünde olduğu Hollanda'da Leuven Üniversitesinde Fransız edebiyatı hocasıdır. Hiç Flamanca bilmemektedir. Derslerini dinlemek isteyen; fakat Fransizca bilmeyen öğrencilere nasıl yardımcı olabileceğini düşünürken imdadına o sırada çift dilli baskısı yapılan Telemak isimli kitap yetişir.
"İ̧̧te 'Zihinsel

Özgürleşme Üstüne

Beş Ders' alt başlığıyla sunulan 'Cahil Hoca' kitabının hikâyesi, 'insanın bilmediğini de öğretebileceği'ni muştulayan bu deneyle başlar." Jacotot, Telemak’ı öğrencilere dağıtır. Anadillerindeki çeviriyle metnin Fransızcasını karşılaştırıp okuyarak anlamaya çalışmalarını ister. Sonuçta Telemak'ı çift dilli baskıdan okumaya çalışan öğrencilerin Fransızcayı anlama ve öğrenme hızı, başta Jacotot olmak üzere herkesi şaşırtır. İşte “Zihinsel Özgürleşme Üstüne Beş Ders” alt başlığıyla sunulan "Cahil Hoca” kitabının hikâyesi, "insanın bilmediğini de öğretebileceği”ni muştulayan bu deneyle başlar.

Günümüzde hâkim pedagojik eğilim, eğitimde "öğretmen”in merkezi konumunun değişmesi gerektiği yönündedir. Buna göre, eğitimin öğretmen değil, "öğrenci merkezli” olması ve öğretim yerine kendi kendine "öğrenme"nin esas olması gerekmektedir. $\mathrm{Bu}$ gereklilik genellikle bilgiye erişimin kolaylaşmış olması ve bilgideki yığılma ve değişim oranlarının artmış olması ile açıklanmaktadır. Belli bir alanda bile sürekli artan ve değişen bilgiyi kontrol etmek güçleşmiştir. Öğretmenin her şeyi bilmesi mümkün değildir artık. Bu nedenle, öğrenmeyiöğretmek ya da araştırmayı öğretmek temel olmalıdırki, araştırma temelli eğitim ya da proje temelli eğitim yaklaşımlarının uygulamada yaygınlaşmasında da bu durum etkilidir. Pedagojik anlayıştaki bu değişiklikler, öğretmen yetiştirme alanında da karşılık bulmaktadır. Öğretmenin, “öğrenen öğretmen” olduğu, kendisini böyle görmesi gerektiği çünkü gelinen durum itibarıly kendisini sürekli geliştirmesi, öğrenmeye açı olması gerektiği düşünülmektedir. "Cahil Hoca" ifadesindeki oksimorona benzer bir durum vardır, "öğrenen öğretmen" ifadesinde de. Benzerlik, sadece öğreticiye verilen isimlerdeki oksimoronda değildir, yaklaşımların kimi özellikleri de birbirine benzemektedir. Örneğin; 'bilmeden kaynaklanan bir hiyerarşi yoktur. Öğrenme basitten karmaşığa doğru sıralı şekilde gitmek zorunda değildir, isteyen kendi sırasina göre öğrenebilir. Öğrenme hocanın açıklamasına dayalı değil, öğrencinin araştırmasına ve ilişkilendirmesine dayalıdır' gibi benzerlikler hatta ortaklıklar vardır, güncel hâkim pedagojik 
Jacques Rancière

\section{Le maître ignorant \\ Cinq leçons sur l'émancipation intellectuelle}

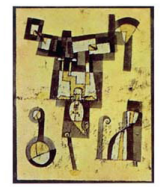

yaklaşımlar ile Cahil Hoca'nın yaklaşımı arasında. Ayrıca, araştırma ve/veya proje temelli eğitim yaklaşımları, konu temelli olmamaları, belli bir müfredata dayalı olmamaları açısından da Cahil Hocánın "özgürleştirici" ve "evrensel eğitim"2 anlayışına benzemektedir. 19. yüzyılın başlarında Jacotot tarafından yapılan felsefi bir deneyin ve bunun üzerine 20. yy. sonlarında Rancière tarafından inşa edilen yaklaşımın pedagojide ve öğretmen yetiştirmede gelinen bu hali çok önceden öngörebilmiş, daha doğrusu önerebilmiş olması şaşırtıcı gelebilir. Fakat şaşırtıcı bir şey yoktur, "yeryüzünde açıklayan bir hoca olmaksızın, kendi başına bir şey öğrenmemiş kimse yoktur” (Rancière, 2014, s. 22) çünkü. ${ }^{3}$

Rancière "bilme/bilgi ile iktidar arasındaki ilişki”" (Badiou, 2015, s. 146) ve "eşitlik ilkesi" (Rancière, 2014, s. 35) üzerine kafa yormaktadır ve şüphesiz, bilme/bilgi ile iktidar arasındaki ilişkinin en iyi ifade bulduğu yer, hocanın/öğretmenin konumudur. Bilme/bilginin iktidar yaratması durumunda eşitlik ${ }^{4}$ ortadan kalkmaktadır. Bu nedenle Rancière, "bilen ile bilmeyenin" eşitliği ve "zekâların eşitliği” (Rancière, 2014, s. 46) üzerinde durmakta ve bunları savunmaktadır. ${ }^{5}$ Çünkü Badiou’nun (2015, s. 158), Rancière'in Cahil Hoca düşüncesini özetlerken belirttiği gibi, "bir cahil hocanın otoritesi altında, bilme eşitliğe mahal teşkil edebilir.” Yine Badiou'nun ifadesine dayanarak eşitlik koşulu altında "cehaletin yeni bir bilmenin doğabileceği nokta"

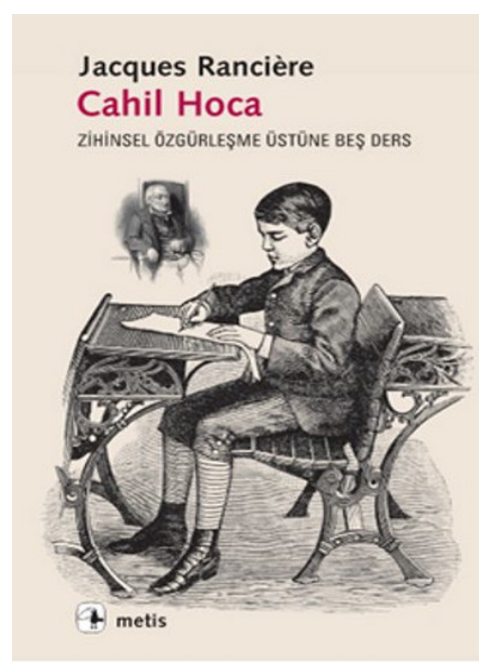

2 Kılıç (2015), "evrensel eğitim” tamlamasındaki evrensel kavramının, "toplumsal sınıf ayrımı yapmaksızın herkes için eğitim” anlamında olduğunu belirtmektedir.

3 Benzerliklere ve ortaklıklara rağmen, Cahil Hocánın “evrensel eğitim” anlayışına yönelik -özellikle eğitimin ilk senelerindeki öğrenciler için ya da bazı derslerin öğretimi açısından- uygulamada yeterli olmadığı yönünde bazı eleştiriler de yapılmaktadır (Eleştiriler için bknz. Hewlett, 2018, s. 122-123). Fakat bu eleştirileri değerlendirirken, "evrensel eğitim"in kurumsal ve toplumsal bir program önermediğini, bireysel düşünseme ve uygulamaya, insanın kendi kendisini eğiterek özgürleşmesine yönelik bir yaklaşım olduğunu hatırlamak yerinde olacaktır. Ayrıca eleştirilerin, uygulamanın sonuçlarıyla ilgili deneyim, gözlem ve araştırmalara değil; uygulama önerisi üzerine yapılan tartışma ve varsayımlara dayalı olduğu gözden kaçırılmamalıdır. Son olarak; benzer eleştirilerin uygulamadaki pedagojik yaklaşımlar için de geçerli olduğunun farkında olunmalıdır.

4 Rancière’e göre "eşitlik ulaşılacak hedef değil, bir hareket noktası, her türlü koşulda savunulması gereken bir varsayım'dır." (age, s. 135).

5 “Zekâların eşitliği”nin, Cahil Hoca’nın en fazla tartışılan önermesi olduğu söylenebilir. Rancière, zekâ ile "zihinsel tezahürlerin eşitsizliği”nin (age, s. 54) birbirine karıştırıldığını; aslında zekânın herkeste eşit olduğunu; fakat bütün kişilerin aynı iradeyi göstermemesi nedeniyle zihinsel tezahürlerde ortaya çıkan farklılığın zekâların eşitsizliği olarak görüldüğünü belirtmektedir. Rancière, "hükmetmek isteyenlerin ortak silahı" olarak bölme’ye (age, s. 31) başvuranların kendi çıkarlarına uygun olarak zekâyı da aşağı-üstün gibi böldüğünü belirterek, böylece insanlar arasında eşitliğin ortadan kalktığına ve "zihinsel aristokrasi”nin (age, s. 112) egemenliği altında üstün olanların aşağı olanları yönetme/yönlendirmede kendini haklılaştırdığına vurgu yapmaktadır. Bu bağlamda zekâları eşitsiz görme eğiliminin temellerine, örneğin; "eşitsizlik kurmacası", "eşitsizliğin rasyonelleştirilmesi” (age, s. 127) gibi konular üzerinde durarak, dikkat çekmektedir. 
olduğu söylenebilir ki bu, eğitimin geleceği için "bütün mümkünlerin kıyısı" sayılabilir.

\section{The Ignorant}

\section{Schoolmaster}

Five Lessons in

Intellectual Emancipation

Cahil Hoca, Rancière'in farklı dillere en çok çevrilen kitabı (Wetzel ve Claviez, 2016'dan akt., Erkek, 2019). Bizzat Cahil Hoca’da yazdığ gibi "anlamak, tercüme etmekten başka bir şey değildir" (Rancière, 2014, s. 16) diye düşünürsek dünyanın dört bir tarafında belki yüzbinlerce insan için Cahil Hoca'yı yeniden yeniden okuyarak tercüme etmenin yani anlamaya çalışmanın kendisi de "zekâların eşitliği”nin başka bir göstergesi olarak görülebilir. Ne de olsa "kitabın demokrasisi" herkesin kendi kendine okuyup öğrenebileceği vaadini içerir ve bu yüzden "kitap zekâların eşitliği”nin işaretidir (Rancière, 2014, s. 43). O zaman biz de bir kere daha okuyalım, tüm insanlara "bilmediğini öğretme yolunu haber vermek" için (Rancière, 2014, s. 105).

\section{Kaynakça:}

Badiou, A. (2015). Fransız felsefesinin macerası, 1960’lardan günümüze. (P. B. Yalım, Çev.) İstanbul: Metis Yayınları.

Erkek, F. (2019). Jacques Rancière. I. B. Bravo, H. Bravo, B. Alan Sümer (Ed.), Çağdaş Fransız Felsefesi içinde (s. 361-391). Ankara: Phoneix Yayınevi.

Hewlett, N. (2018). Badiou, Balibar, Rancière, Özgürleşmeyi yeniden düşünmek. (H. İ. Mavituna, Çev.) İstanbul: Metropolis Yayıncılık.

Kılıç, S. (2015). Cahil Hoca'nın “İmkânsız” Eğitimi. Birikim Dergisi, 311, 1-7. https://www.academia. edu/11935482/CAH\%C4\%B0L_HOCANIN_\%C4\%B0MKANSIZ_E\%C4\%9E\%C4\%B0T \%C4\%B0M\%C4\%B0 adresinden 27 Temmuz 2020 tarihinde alınmıştır.

Rancière, J. (2014). Cahil hoca: Zihinsel özgürleşme üstüne beş ders. (S. Kılıç, Çev.) İstanbul: Metis Yayınları. 


\section{Demokrasi sorumluluktur.}

Qeni yafinaz Kutfu of sun.

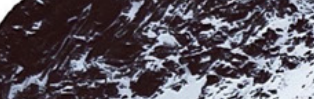

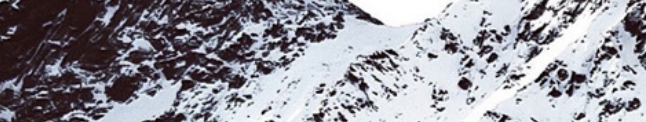
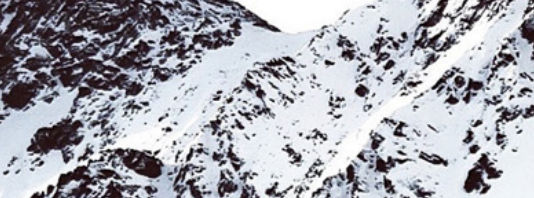

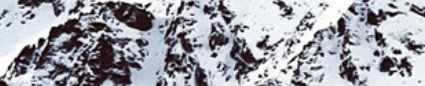

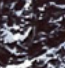

it:

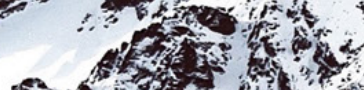

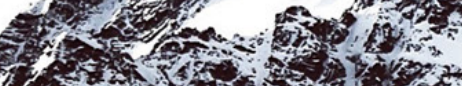
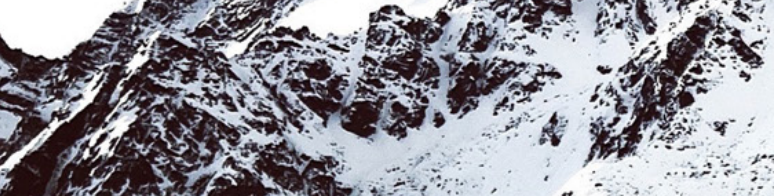

a
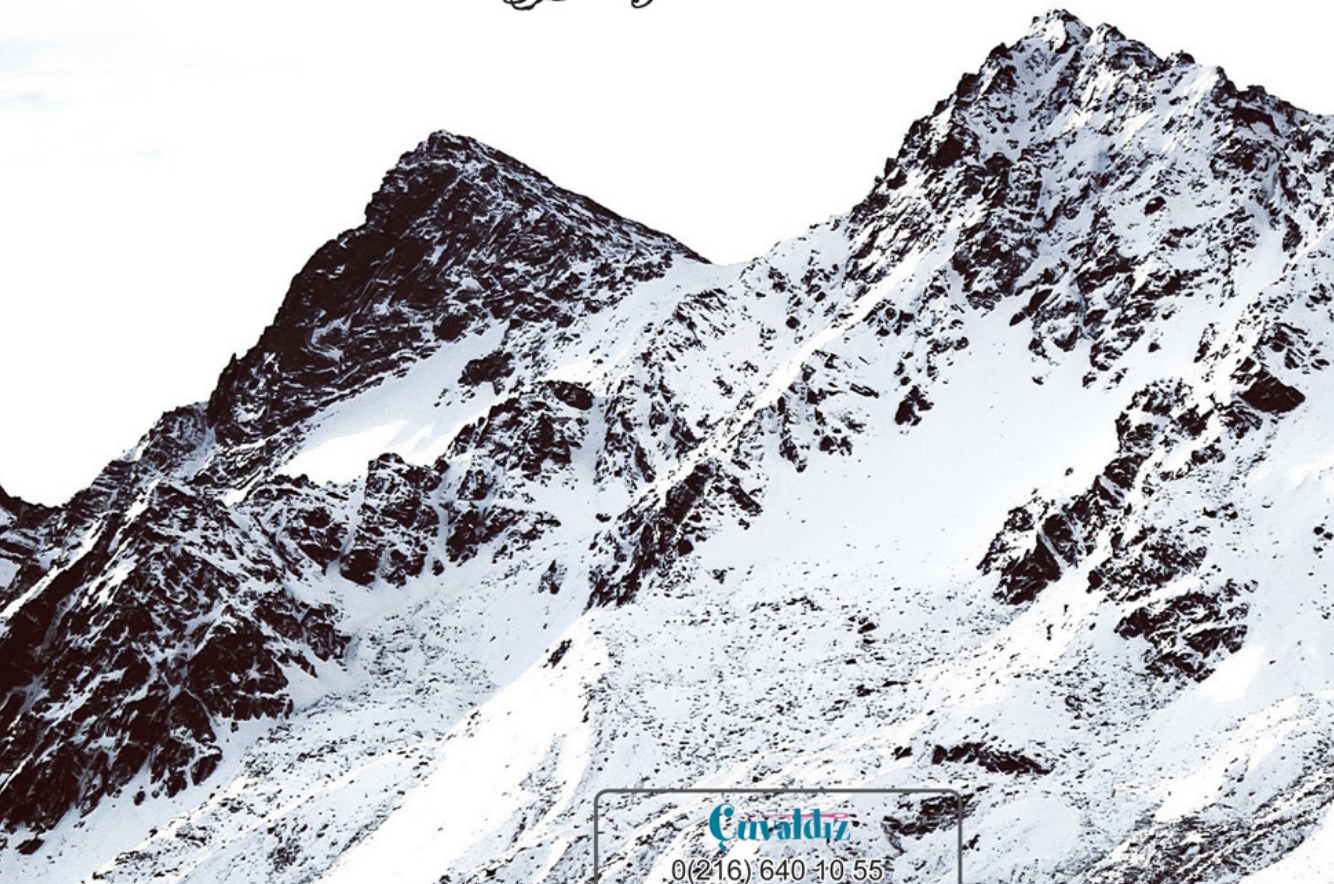

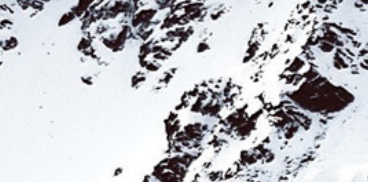

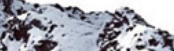

